\title{
Makna Ketaatan Menurut Kitab Daniel
}

\section{The Meaning of Obedience According to the Book of Daniel}

\author{
Aldorio Flavius Lele ${ }^{1)^{*}}$ \\ 1) Sekolah Tinggi Filsafat Theologia Jaffray Makassar \\ *Penulis Korespondensi: aldorio1891@gmail.com
}

Received: 1304 2021/Accepted: 2510 2021/Published: 01122021

\begin{abstract}
Abstrak
Daniel adalah salah satu tokoh Alkitab yang dikenal karena konsistensinya dalam menaati perintah Tuhan. Salah satunya adalah dengan tidak menajiskan dirinya dengan santapan raja Nebukadnezar (Dan. 1:8). Ketaatan Daniel ditunjukkan melalui ketetapan hatinya kepada Tuhan yang tidak berubah sekalipun situasi dan kondisi berubah begitu drastis. Menariknya, kata Ibrani syama yang diterjemahkan "taat" dalam kitab Daniel hanya muncul sekali dalam keseluruhan kitab ini (Dan. 9:6). Meskipun demikian, sebagian besar hikayat dalam kitab Daniel memuat tema tentang ketaatan yang begitu nyaring. Hal ini nampak dalam setiap tindakan para tokoh yang mengasihi Allah secara khusus Daniel. Tujuan dari penelitian ini adalah untuk membawa pembaca memahami dan mendalami konsep ketaatan dari sudut pandang kitab Daniel melalui pendekatan hermeneutik biblika. Berdasarkan hasil uraian dan analisis penulis tentang ketaatan menurut kitab Daniel, maka kesimpulan yang diperoleh adalah sebagai berikut: ketaatan menurut kitab Daniel didasarkan pada pengenalan yang benar akan TUHAN, pengakuan iman dan penyangkalan diri. Dengan demikian, maka ketaatan berarti mendengarkan apa yang TUHAN katakan; menjauhi apa yang la larang serta melakukan dengan setia apa yang la perintahkan. Jadi, ketaatan berbicara tentang sebuah relasi, yakni hubungan seseorang dengan TUHAN dan doa adalah kunci untuk memulai sebuah hubungan pribadi dengan TUHAN.
\end{abstract}

Kata-kata Kunci: Daniel, Ketaatan, Kitab Daniel, Makna, Relasi.

\begin{abstract}
Daniel is one of the biblical figures known for his consistency in terms of God's commandments. One of them is not to defile himself with the food of King Nebuchadnezzar (Dan. 1:8). Daniel's obedience was shown by remaining steadfast to God who did not change even though the situation and conditions changed so drastically. Interestingly, the Hebrew word shama which is translated simply "obedient" in Daniel appears once in the entire book (Dan. 9:6). Nevertheless, most of the stories in the book of Daniel contain the big theme of obedience so loud. This is seen in every action of the characters who represent God specifically Daniel. The purpose of this
\end{abstract}


study is to understand and explore the concept of observation from the perspective of the book of Daniel through a biblical hermeneutic approach. Based on the results and the author's analysis of obedience to the book of Daniel, the conclusions obtained are as follows: obedience to the book of Daniel is based on true knowledge of God, confession of faith and self-denial. Thus, obedience means paying attention to what God says; supports what he forbids and faithfully does what he commands. So, the relationship of obedience speaks of a relationship, namely a person with God and prayer is the key to starting a personal relationship with God.

Keywords: Daniel, Obedience, Relationship, The book of Daniel, The Meaning.

\section{PENDAHULUAN}

Ketaatan adalah salah satu hal yang menjadi bagian utama dalam perjalanan iman seorang Kristen kepada Tuhan. Ketaatan adalah bukti bahwa seseorang telah mengalami perubahan radikal di dalam dirinya. Bagi mereka yang mengenal Allah dan mengalami kasih Allah-Nya, ketaatan menjadi salah satu ciri perubahan tersebut.

Ketaatan secara literal berarti tunduk pada kemauan atau otoritas orang lain dengan melaksanakan perintah atau instruksi dan berperilaku sesuai dengan prinsip umum atau hukum kodrat yang diberikan. Menurut Bromiley, kata ini memiliki arti yang tumpang tindih seperti yang ditunjukkan dalam berbagai terjemahan kata Ibrani dan Yunani dan juga oleh pararelisme sinonim yang sering digunakan (mis. Mzm. 17:1; Yes. 28:23; 42:23; Yer. 23:18; Bromiley, 2002, p. 649). Akan tetapi secara umum dapat disimpulkan bahwa konsep ini sebenarnya diterjemahkan dari Bahasa Ibrani "mendengar" (Kej. 22:18; Yes. 42:24) yang diekspresikan sebagai "menaati" atau "mengamati" perintah (Kel. 16:28; 34:11) dan "berjalan" di jalan Tuhan (1 Raj. 11:33; Achtemeier, 1985, p. 717). Jadi ketaatan berhubungan dengan mendengarkan, mengamati dan melakukan perintah Tuhan. Dengan demikian pengenalan yang benar akan Allah, pengetahuan yang dalam tentang firman dan pengalaman yang utuh tentang kasih karunia Allah menjadi landasan atau dasar sebuah ketaatan. Jadi ketaatan selalu berkaitan dengan sejauh mana seseorang mengenal Tuhan. Dengan kata lain, ketaatan tanpa pemahaman, pengetahuan dan pengalaman hanyalah sebuah ketaatan yang berpusat pada diri sendiri.

Ketaatan orang percaya dalam kitab Daniel memberikan makna yang mendalam tentang ketaatan itu sendiri yang terlihat dalam setiap tindakan, perkataan, keputusan dan sikap mereka yang mengasihi Tuhan. Jika ketaatan itu tidak dilandaskan pada kasih, maka hal itu tidak pantas disebut sebagai ketaatan. Tanpa kasih, ketaatan hanya akan menjadi sebuah ajang untuk memamerkan diri sendiri. Tanpa adanya kasih, ketaatan itu identik dengan kemunafikan. Sebaliknya, jikalau ketaatan dilandasi oleh kasih, maka seseorang akan rela melangkah lebih jauh daripada tuntutan minimum. Intinya, kasih memampukan seseorang untuk 
melangkah lebih jauh daripada yang diharapkan oleh orang lain. Dengan demikian, ketaatan seharusnya merupakan respons terhadap kasih Allah dan wujud kasih seseorang kepada-Nya. Tanpa Allah yang terlebih dahulu mengambil inisiatif untuk mengasihi, tidak mungkin seseorang mampu mengasihi Dia, apalagi menaati Dia. Bertolak dari prinsip ini, maka penelusuran terhadap konsep ketaatan berdasarkan kitab Daniel menjadi hal yang masuk akal dan dapat dijelaskan.

\section{METODE}

Penelitian ini menggunakan metode penelitian kualitatif dengan penalaran secara induktif (Lumintang, 2016, p. 95) dan penerapan prinsip-prinsip dan metode hermeneutik biblika (penafsiran Alkitab) yang secara sederhana dapat didefinisikan sebagai metode penafsiran yang bertujuan untuk menemukan maksud yang ingin disampaikan oleh penulis Alkitab (Sutanto, 2007, p. 8). Fokus pendekatan ini yang mengacu pada teks kitab Daniel, sehingga prinsip kebenaran yang ditemukan memperjelas makna dan juga memberikan kesimpulan analisis penelitian tentang konsep ketaatan menurut kitab Daniel (Fisher, 1987, 113).

\section{HASIL DAN PEMBAHASAN}

\section{Analisis Makna Ketaatan Menurut Kitab Daniel}

Sejarah yang ada dalam Kitab Daniel secara keseluruhan memuat aspek teologis, karena menyatakan bahwa TUHAN adalah satu-satunya Tuhan atas sejarah, yang di dalamnya mengungkapkan kekuatan, kuasa dan keagungan kerajaan-Nya, serta Tuhan yang mengendalikan jalannya peristiwa dalam sejarah besar kerajaan dunia (Parchem, 2018, pp. 121-44). Selain itu, hal yang paling menonjol dalam kitab ini adalah tentang tokoh bernama Daniel dengan kemampuan atau hikmatnya serta mimpinya yang lebih bermuatan tema eskatologis (Putri, 2017, p. 156). Jadi dengan melihat adanya aspek teologis dan eskatologis, maka penulis memusatkan pemahaman pada tindakan Allah yang terjadi di dalam sejarah yang ada di Kitab Daniel serta berfokus pada sikap Daniel yang menjadi teladan dalam hal ketaatan kepada Allah. Oleh karena itu, kerangka analisis makna ketaatan dalam kitab Daniel, dimulai dengan menyoroti penggunaan kata "taat" yang ada dalam Kitab Daniel untuk menyimpulkan makna teologis yang terkandung di dalamnya.

\section{Makna Leksikal}

Kata "taat" secara literal yang ada dalam kitab Daniel terdapat dalam Daniel 9:6.

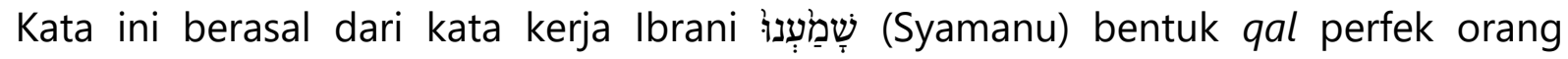
pertama jamak (Kelley, 2013, p. 93) dari kata dasar שמע (Syama) yang secara harfiah berarti hear, listen to, heed, obey, dan understand (Strong, 2017, s.v. "shama"). Beberapa ayat dalam Terjemahan Baru, menerjemahkan kata ini sebagai "dengar", 
"didengarkan", dan "mendengarkan" (bdk. Dan. 1:14, 8:13,16; 9:6,10,11,14,17,18,19; $10: 9,12$; 12:7,8; perbedaan yang ada disesuaikan dengan bentuk kata kerja yang digunakan serta konteks). Dalam beberapa kasus, kata syama tidak berarti hanya mendengar apa yang dikatakan, tetapi juga menyetujui maksud dan tujuan yang dikatakan. Karena itu, ketika kata ini merujuk pada otoritas tertinggi sebagai objek, maka kata syama dapat berarti taat atau patuh terhadap otoritas tersebut (Strong, 2017, s.v. "shama").

Di dalam teks Daniel 9:6, frasa "taat" yang digunakan didahului oleh kata וְלְא (Bibleworks 10, s.v. "welo") yang terdiri dari dua suku kata yaitu ? (we) yang merupakan awalan penghubung (particle conjunction) yang berarti "dan, tetapi, maka, Ialu" (Baker, Siahaan dan Sitompul, 2015, p. 61) dan kata לא (lo) yang merupakan kata deklarasi tindakan negatif (particle negative) yang berarti "tidak" atau "bukan" (Baker, Siahaan dan Sitompul, 2015, p. 39). Dengan adanya penghubung serta unsur negatif di awal kalimat, maka, ketaatan yang dimaksud pada bagian ini adalah bentuk negatif atau lawan kata atau kebalikan dari maksud positif kata "taat" yakni ketidaktaatan.

Frasa "tidak taat" dalam ayat ini merupakan salah satu ungkapan yang diucapkan oleh Daniel dalam doanya kepada TUHAN sebagai sebuah pengakuan untuk memohon pengampunan dan belas kasihan TUHAN atas dosa dan kesalahan dirinya dan bangsanya. Pengakuan tersebut antara lain perbuatan dosa dan salah, berlaku fasik dan telah memberontak, menyimpang dari perintah dan peraturan TUHAN (ay. 5), serta ketidaktaatan yang ditunjukkan melalui sikap tidak mau mendengar suara TUHAN yang telah disampaikan oleh para nabi (ay. 6). Bahkan 4 kali Daniel mengakui bahwa umat-Nya telah berbuat dosa (Dan. 9:5,8,11,15). Dosa mereka adalah dosa pemberontakan (ay. 9) melawan Allah dan karena berpaling (ay. 11) dari Firman Allah (hukum-hukum-Nya; lih. ay. 10-11) yang mereka ketahui (Walvoord dan Zuck, 1985, p. 1360). Mereka yang termasuk dalam pemberontakan ini adalah raja-raja Israel, para pemimpin-pemimpin Israel, bapa-bapa Israel dan segenap rakyat negeri termasuk kaum Yehuda dan Daniel (lih. Dan. 9:5-19).

Dengan demikian bentuk perfek pada kata kerja Syamanu dan bentuk kata welo yang mendahului, memberikan pengertian sekaligus penekanan bahwa tindakan Daniel dan bangsa Israel (pada waktu lampau) sesungguhnya telah menyatakan penolakan terhadap firman Tuhan (Kelley, 2013, p. 96). Dengan kata lain, pemberontakan melawan Allah. Sekalipun mereka memiliki tulisan-tulisan Musa, mukjizat-mukjizat Keluaran, kemenangan-kemenangan dari penaklukan dan penggenapan dari janji akan tanah kepada Abraham, tetapi mereka tidak menjadi setia (lih. II Raj. 17:13-15; Yer. 44:4,5,21; Hos. 11:2; Utley, 2005, p. 108). Penolakan tersebut ditegaskan dengan sikap tidak setia untuk menaati, mendengarkan, dan memperhatikan perkataan Tuhan yang berakibat penderitaan di bawah pemerintahan Babel.

Oleh karena itu, arti ketaatan dalam bagian ini merupakan kebalikan dari tindakan taat terhadap perintah Tuhan. Sehingga, berdasarkan pemahaman dari 
Daniel 9:6, makna ketaatan yang seharusnya adalah melakukan hal yang benar (tidak berbuat dosa dan salah), berlaku baik, menurut, tidak menyimpang dari aturan dan perintah, mendengarkan perintah TUHAN dan melaksanakannya.

\section{Aspek Ketaatan Menurut Kitab Daniel}

Berawal dari pemahaman terhadap penggunaan kata "taat" dalam Daniel 9:6, penulis menemukan ada beberapa aspek yang mendasari nilai sebuah ketaatan dalam kitab Daniel.

\section{Pengenalan akan Allah}

Pengenalan Daniel akan siapa Allah terlihat dalam penyebutan-penyebutan nama Allah yang digunakan dalam doanya. Daniel menyebut Allah dengan menggunakan beberapa sebutan, di antaranya:

1) "TUHAN" (ay. 2,8,10,13,14). Ini adalah pertama kalinya nama TUHAN, yakni יהזוֹ (Yahweh) disebutkan dalam Kitab Daniel (Bibleworks 10, s.v. "Yahweh"). Dalam doanya di pasal 9:1-19, Daniel menyebut Allah dengan nama Yahweh sebanyak enam kali (Daniel 9:2,8,10,13,14 dua kali). Ketika Daniel menggunakan kata Yahweh untuk memanggil Allah, maka hal ini menyatakan penyebutan Allah yang khusus bagi bangsa Israel, yang bersifat kasih dan setia sekaligus menyatakan hubungan dan pengenalan Daniel yang begitu intim dengan TUHAN (Newel, 2000 , p. 243). Berdasarkan penyebutan nama TUHAN ini, maka dapat disimpulkan bahwa Ketaatan Daniel kepada TUHAN dilandasi oleh pengenalan dan hubungan pribadi Daniel dengan TUHAN.

2) Tuhan Allah (ay. 3). Kata Adonay yang digunakan dalam ayat ini berarti my Great Lord (Tuanku yang besar). Sebutan ini adalah sebuah gelar kehormatan yang digunakan untuk menyebut atasan social (Achteimeir, 1985, p. 686). Selain itu, sebutan ini merupakan sebutan yang diucapkan menggantikan Yahweh dalam tampilan penghormatan orang Yahudi terhadap nama TUHAN (Strong, 2017, s.v. "adonay"). Jadi dengan menyebut Adonay, Daniel menunjukkan sikap hormat yang tinggi terhadap nama TUHAN. Sedangkan, kata elohim merupakan sebutan umum yang digunakan untuk nama Tuhan dalam Perjanjian Lama (Achteimeir, 1985, p. 686). Frasa ini menyatakan kuasa dan kekuasaan TUHAN sebagai Allah atas langit dan bumi (hal ini dapat dipahami ketika melihat respons Daniel yang mengarahkan mukanya kepada Tuhan Allah untuk berdoa dan bermohon, sambil berpuasa dan mengenakan kain kabung serta abu. Lih. Dan. 9:3). Jadi dengan menyebutkan nama Tuhan Allah, Daniel memproklamasikan Yahweh sebagai atasan tertinggi dan mulia atas segala ciptaan.

3) TUHAN, Allahku (ay. 4). Ungkapan ini menjelaskan bahwa TUHAN, Allah adalah pribadi yang disembah oleh Daniel. Frasa ini menyatakan kepemilikan. Dengan maksud, secara pribadi, Daniel mengakui bahwa TUHAN adalah Allahnya, tempat 
bersandar dan berharap untuk memohon pengampunan akan dosanya (lih. Dan. 9:4).

4) Ya Tuhan (ay. 7,16,19). Frasa ini beserta keterangan dalam teks menyatakan Tuhan yang benar, penuh belas kasih, dan kudus (ay. 7) menyebutkan bahwa Tuhan yang dipanggil oleh Daniel adalah Tuhan yang benar. Ayat 16 menyatakan Tuhan yang berbelas kasihan dan Tuhan yang murka, serta Tuhan yang kudus. Jadi Daniel memahami Tuhan sebagai Allah yang penuh dengan belas kasihan dan juga kekudusan, itulah sebabnya oleh karena dosa umat Israel, Tuhan menghukum bangsa ini dengan murka dan amarah. Ayat 19 memberikan gambaran Tuhan yang mendengar, Tuhan yang pengampun, Tuhan yang memperhatikan dan bertindak oleh karena diri-Nya sendiri. Kasih, kekudusan serta keadilan Allah nampak dalam semua sifat yang disebutkan Daniel melalui nama Allah yang digunakannya. Sehingga ungkapan "Ya Tuhan" menyatakan kebergantungan Daniel terhadap pribadi Tuhan yang benar dan berkuasa.

5) Tuhan, Allah kami (ay. 9,10,13,14,15). Frasa ini menyatakan bahwa bukan hanya Daniel seorang yang dipanggil dalam hubungan khusus dengan TUHAN, melainkan semua umat Israel yang mempunyai hubungan perjanjian dengan Dia (Newel, 2000, p. 243).

6) Ya, Allah kami (ay. 17). Frasa ini berhubungan dengan permohonan Daniel agar TUHAN menyinari tempat kudus-Nya yang telah musnah (lih. frasa "... dan sinarilah tempat kudus-Mu yang telah musnah ini..."). Bagian ini menyatakan harapan Daniel terhadap pemulihan Yerusalem. Menariknya, Daniel tidak merincikan apa yang harus Tuhan lakukan; dia hanya meminta agar Tuhan "melihat" tempat kudus dan "melihat" kota, keduanya berada dalam kesunyian selama bertahun-tahun (Walvoord dan Zuck, 1985, p. 1360). Kata selanjutnya yang digunakan ialah, "demi Tuhan sendiri". Kata ini menyatakan dasar harapan Daniel kepada TUHAN serta tujuan Daniel memohon. Kedua motif ini berfokus pada diri Tuhan sendiri, dari Tuhan, oleh Tuhan dan untuk Tuhan (Dan. 6:17, "Oleh sebab itu, dengarkanlah, ya Allah kami, doa hamba-Mu ini dan permohonannya, dan sinarilah tempat kudus-Mu yang telah musnah ini dengan wajah-Mu, demi Tuhan sendiri"). Jadi, Daniel mendasarkan permintaannya pada belas kasihan Allah yang besar (ay. 9), bukan pada kebenaran bangsa itu karena mereka tidak memilikinya. Tetapi karena Tuhan itu pengasih dan pengampun, dia berdoa, ya Tuhan, dengarkanlah! Ya Tuhan, ampunilah! Prihatin dengan reputasi Tuhan, Daniel ingin Tuhan bertindak cepat (tidak menunda) atas nama kota dan orang-orang yang memakai nama-Nya. Semua ini akan membawa kemuliaan bagi Allah karena itu adalah demi Dia (lih. ay. 17; Walvoord dan Zuck, 1985, p. 1360). Dengan demikian penyebutan Allah kami menyatakan kepentingan Allah di dalam pemulihan bangsa Israel.

7) Ya, Allahku (ay. 18). Hampir tidak ada doa lain dalam Kitab Suci yang begitu mendesak. Tuhan dipanggil untuk membebaskan umat Israel yang terbebani oleh dosa dan menderita penindasan tanpa ampun. Allah harus bertindak tanpa 
penundaan demi kepentingan-Nya sendiri (9:17,19), untuk membawa keselamatan bagi kota dan umat-Nya, yang menyandang nama Allah (Lederach, 1994, p. 210).

Berdasarkan semua penyebutan nama Allah dalam pasal 9:1-19, maka dapat dilihat bahwa Daniel memiliki pengenalan yang dalam akan siapa TUHAN yang ia sembah. Berbagai sebutan yang digunakan Daniel untuk memanggil Allah menyatakan bahwa Allah adalah sosok tertinggi dan terutama dalam segala sesuatu. Sifat-Nya, karakter-Nya, keputusan-Nya, kedaulatan-Nya, kekuasaan-Nya, serta anugerah-Nya adalah beberapa dari banyak hal yang dimiliki oleh Allah yang disebutkan di sini. Penyebutan nama TUHAN menyatakan bahwa TUHAN adalah Pencipta, Pemilik, dan Pemelihara atas segala sesuatu. Tidak ada sesuatu pun atau oknum mana pun termasuk kesulitan, kesengsaraan, penindasan bahkan pemerintahan baru yang memiliki otoritas lebih tinggi atau lebih besar dari TUHAN. Harapan Daniel terpancar melalui semua sebutan ini, sehingga melalui penyebutan nama Tuhan yang dipakai oleh Daniel dalam doanya ada beberapa hal penting yang dinyatakan: 1) Daniel menyatakan siapa TUHAN yang ia sembah; 2) Daniel menyatakan sejauh mana pengenalannya akan TUHAN; 3) Daniel menyatakan seberapa besar keyakinannya kepada TUHAN. 4) Daniel menyatakan apa yang menjadi dasar ketaatannya kepada TUHAN.

\section{Pengakuan Akan Allah}

Pengakuan Daniel akan Allah ditunjukkan melalui penyebutan sifat-sifat Allah yang menyertai penyebutan nama TUHAN dalam pasal 9:1-19. Adapun sifat-sifat itu antara lain:

1) Tuhan, Allah yang maha besar dan dahsyat (ay. 4)

2) Tuhan, Allah yang memegang perjanjian dan kasih setia (ay. 4)

3) Ya Tuhan, Engkaulah yang benar (ay. 7)

4) Ya Tuhan, Allah, ada kesayangan dan keampunan (ay. 9)

5) TUHAN, Allah, yang menyuruh hidup menurut hukum yang telah diberikan-Nya. (ay. 10).

6) TUHAN, Allah, adalah adil dalam segala perbuatan yang dilakukan-Nya (ay. 14)

7) Tuhan, Allah yang telah membawa umat-Nya keluar dari tanah Mesir dengan tangan yang kuat dan memasyurkan nama-Nya (ay. 15)

Selain itu, dalam ayat-ayat yang lain Daniel juga menyatakan bahwa Allah adalah: Allah Semesta langit (2:18); Allah yang daripada-Nyalah hikmat dan kekuatan (2:20); Allah yang mengubah saat dan waktu, memecat raja dan mengangkat raja, memberi hikmat kepada orang yang bijaksana, memberi pengetahuan kepada orang yang berpengertian (2:21); Allah yang menyingkapkan hal-hal yang tidak terduga, dan yang tersembunyi, Allah yang tahu apa yang ada di dalam gelap, terang ada pada-Nya (sumber terang; 2:22), Allah yang layak menerima segala pujian dan kemuliaan (2:23); Allah yang ada di Sorga, yang menyingkapkan rahasia-rahasia yang 
memberikan mimpi kepada raja dan memberitahukan arti mimpi kepada Daniel (2:28), Allah semesta langit yang memiliki kerajaan, kekuasaan, kekuatan dan kemuliaan, dan yang telah menjadikan anak-anak manusia, menciptakan binatangbinatang di padang dan burung-burung di udara, dan yang berkuasa atas semuanya itu (2:37-38). Allah semesta langit (2:44); Allah yang Maha Besar (2:45); Allah, Yang Maha tinggi, berkuasa atas kerajaan manusia dan mengangkat siapa yang dikehendaki-Nya untuk kedudukan itu (5:21). Allah yang berkuasa di sorga; Allah, yang menggenggam nafas dan menentukan segala jalan raja (5:23); Allah yang telah mengutus malaikat-Nya (6:23); Tuhan, Allah yang maha besar dan dahsyat, yang memegang Perjanjian dan kasih setia (9:4); Tuhan, Allah yang penyayang dan pengampun (9:9); TUHAN, Allah yang adil dalam segala perbuatan yang dilakukanNya (9:14); Tuhan, Allah yang telah membawa umat-Nya keluar dari tanah Mesir dengan tangan yang kuat dan memasyhurkan nama-Nya (9:15); Allah yang Kudus (9:17); Allah yang berlimpah kasih sayang (9:18).

Pengakuan akan Allah bukan saja keluar dari mulut Daniel, tetapi juga dari beberapa tokoh utama yang ada dalam kitab ini.

1) Pengakuan Sadrakh, Mesakh, dan Abednego, "Allah yang sanggup melepaskan dari perapian yang menyala-nyala dan dari tangan raja" (3:17)

2) Pengakuan Nebukadnezar, "Allah yang mengatasi segala allah dan Yang berkuasa atas segala raja, dan Yang menyingkapkan rahasia-rahasia, sebab engkau telah dapat menyingkapkan rahasia itu." (2:47); Allah yang Maha Tinggi (3:26); Allah yang terpuji (3:28); tidak ada allah lain yang dapat melepaskan seperti Allah Sadrakh, Mesakh, dan Abednego (3:29); Allah yang Maha Tinggi yang melakukan tanda-tanda dan Mujizat (4:2). Pengakuan Nebukadnezar mendukung teologi yang sesuai mengingat konteks sastra Daniel yang lebih luas. Pemahaman Raja tentang TUHAN telah dikonversi ke persepsi Daniel tentang Tuhan (Rindge, 2010, p. 85).

3) Pengakuan Raja Darius, Allah yang harus ditakuti oleh seluruh kerajaan; Allah yang hidup, yang kekal untuk selama-lamanya; pemerintahan-Nya tidak akan binasa dan kekuasaan-Nya tidak akan berakhir. Allah yang melepaskan dan menolong, dan mengadakan tanda dan mujizat di langit dan di bumi, Allah yang telah melepaskan Daniel dari cengkraman singa-singa (6:27-28). Hal yang menarik dari pengakuan dua raja di atas ialah bahwa mereka tidak menggunakan nama khusus Allah (Yahweh) dan juga oleh Daniel ketika berbicara kepada mereka. Hal ini menunjukkan bahwa nama "Yahweh" tidak dipakai oleh orang bangsa kafir yang bukan umat-Nya (Newel, 2000, p. 244).

4) Pernyataan Malaikat, "Allah yang mengatasi segala allah" (11:36).

Jadi, melalui pengakuan beberapa tokoh mengenai siapa Allah, sesungguhnya menyatakan betapa pentingnya pengakuan akan Allah. Penulis mengambil dasar dari pernyataan malaikat kepada Daniel sebagai kesimpulan dari bagian ini bahwa, "umat yang mengenal Allahnya akan tetap kuat dan akan bertindak" (11:32). Pengakuan Daniel, Hananya, Misael, Azarya tentang siapa Allah telah memberikan pengaruh 
yang sangat besar kepada seluruh kerajaan Babel sehingga para raja dan seluruh masyarakat akhirnya mengenal dan mengakui kebesaran Allah. Pengakuan akan siapa Allah menjadi dasar mereka untuk tetap kuat dalam imannya dan memampukan mereka untuk bertindak dalam ketaatan. Sekalipun para raja mengenal Allah tidak secara pribadi, akan tetapi pengakuan mereka memberikan petunjuk bahwa Tuhan juga menyatakan diri-Nya kepada mereka yang bukan umat-Nya. Sekalipun pemahaman mereka sangat terbatas, mereka memberikan pengakuan yang benar tentang Allah. Dengan demikian, Allah dapat memakai ketaatan hamba-hamba-Nya untuk memperkenalkan diri-Nya kepada orang lain. Karena itu ketaatan dalam pengakuan yang benar memberikan kesaksian yang kuat.

\section{Pengenalan akan Diri Sendiri}

Pengenalan akan diri sendiri berpengaruh dalam proses ketaatan, karena melaluinya seseorang disadarkan tentang apa yang harus ia lakukan. Daniel menyadari hal ini sehingga di dalam doanya, ia menyebutkan bahwa:

1) Daniel sadar bahwa dirinya (termasuk bangsanya) adalah orang berdosa yang telah melakukan dosa dan berlaku fasik dan telah memberontak, serta telah menyimpang dari perintah dan peraturan TUHAN, dan juga tidak taat (ay. 4-6).

2) Daniel sadar bahwa Pembuangan di Babel terjadi karena bangsanya berlaku murtad, berdosa, memberontak, tidak mendengarkan suara TUHAN, telah melanggar hukum dan menyimpang sehingga Daniel menegaskan sudah sepatutnya mereka malu di hadapan TUHAN (ay. 7-8).

3) Pada akhirnya, Daniel merasa tidak layak memohon kepada TUHAN, tetapi karena ia mengenal siapa TUHAN serta mengingat janji yang pernah TUHAN adakan dengan nenek moyangnya, maka dengan penuh kerendahan hati dan keberanian, Daniel mengatakan, "Ya Allahku, arahkanlah telinga-Mu dan dengarlah, bukalah mata-Mu dan lihatlah kebinasaan kami dan kota yang disebut dengan nama-Mu, sebab kami menyampaikan doa permohonan kami ke hadapan-Mu bukan berdasarkan jasa-jasa kami, tetapi berdasarkan kasih sayang-Mu yang berlimpahlimpah. Ya Tuhan, dengarlah! Ya, Tuhan, ampunilah! Ya Tuhan, perhatikanlah dan bertindaklah dengan tidak bertangguh, oleh karena Engkau sendiri, Allahku, sebab kota-Mu dan umat-Mu disebut dengan nama-Mu!" (ay. 18-19).

Pengenalan akan diri Daniel menyatakan tiga hal yang penting. Pertama, ia menyadari statusnya sebagai orang bedosa; kedua, ia menyadari dirinya sebagai pelaku dosa; ketiga, ia menyadari ketidaklayakkannya untuk memohon kepada TUHAN. Jadi, dalam bagian ini pengenalan diri yang benar membawa Daniel menyadari siapa dirinya di hadapan TUHAN. Pengenalan ini berdasarkan pengenalan dan pengakuannya akan siapa TUHAN. Dengan maksud, pengenalan dan pengakuan yang benar tentang TUHAN menunjukkan identitas diri yang sebenarnya di hadapan TUHAN. 
Doa Daniel menunjukkan penundukkan dirinya serta harapannya kepada TUHAN karena ia mengenal siapa TUHAN. Ketaatannya kepada TUHAN dilandasi oleh kesadarannya akan siapa dirinya di hadapan TUHAN. Sehingga motivasi Daniel menaati TUHAN bukan berdasarkan siapa dirinya atau kemampuan apa yang dimilikinya, melainkan ia mendasarkan pengharapannya kepada TUHAN berdasarkan siapa TUHAN yang ia kenal dan pengakuannya terhadap apa yang mampu TUHAN lakukan.

\section{Konsepsi Ketaatan Dalam Kitab Daniel}

Ketaatan berarti mendengarkan suara dan perintah orang yang didengarkan (kesimpulan ini berdasarkan makna ketaatan yang telah penulis bahas sebelumnya pada bagian makna dari pengertian welo syamanu). Ketaatan sangat dipengaruhi oleh beberapa aspek yakni siapakah orang yang didengar, pengakuan pribadi terhadap oknum yang didengar serta pengenalan diri yang berujung kepada kesadaran diri di hadapan oknum tersebut (tiga bagian ini berdasarkan pembagian aspek ketaatan yang dijelaskan sebelumnya). Jadi, berdasarkan konsep di atas, ketaatan dapat dikelompokkan dalam dua bagian, yakni: ketaatan kepada Allah Israel sebagai pemegang kekuasaan tertinggi; dan ketaatan kepada Raja Babel sebagai pemegang kekuasaan tertinggi (ketika ketaatan berkaitan dengan tindakan, maka oknum pemegang otoritas tertinggi menjadi objek dari tindakan tersebut. Sehingga berdasarkan otoritas tertinggi dalam kitab Daniel, penulis menemukan ada dua otoritas yang dihormati).

Alkitab mencatat, ketaatan kepada Allah Israel (Yahweh) ditunjukkan melalui sikap dan tindakan yang hanya dilakukan oleh empat orang Yahudi ketika berada dalam pembuangan yaitu; Daniel, Hananya, Misael, dan Azarya yang diubah nama mereka oleh pemimpin pegawai istana Raja Babel menjadi Beltsazar (Daniel), Sadrakh (Hananya), Mesakh (Misael), dan Abednego (Azarya; Dan. 1:7). Selain daripada mereka itu, semuanya tunduk dan taat kepada raja Babel.

Melihat dari respons masing-masing tokoh, penulis menarik kesimpulan bahwa ketaatan seseorang kepada oknum yang berkuasa tergantung dari seberapa "takut"nya mereka terhadap oknum yang memberikan perintah.

Kata "takut" dipakai sebanyak enam kali dalam kitab Daniel (1:10; 5:19; 6:27; $10: 7 ; 12 ; 19)$, namun jika melihat bahasa aslinya, kata "takut" diterjemahkan dari beberapa kata yang berbeda dalam bahasa Ibrani sehingga memiliki pengertian yang berbeda sesuai dengan konteks dalam teks tersebut.

Dalam Daniel 1:10, kata "takut" yang digunakan berasal dari kata ירא (yare') yang berarti fearing, reverent, afraid (takut, hormat; Bibleworks 10, s.v. "yare") yang jika diartikan berdasarkan konteks adalah bahwa pemimpin pegawai istana raja itu "sangat takut" terhadap ketetapan Raja perihal makanan dan minuman yang telah ditentukan bagi orang-orang cakap yang dipilih untuk dididik agar kelak bekerja untuk raja termasuk Daniel, Hananya, Misael dan Azarya. Di satu sisi, ketakutannya itu dikarenakan kekuatirannya terhadap kondisi kesehatan mereka yang menolak 
menyantap santapan raja. Jadi sebenarnya pegawai istana "takut dianggap bersalah oleh raja" karena tidak melaksanakan perintahnya.

Selanjutnya, kata "takut" dalam Daniel 5:19 berasal dari kata, דחל (dekhal) yang berarti to fear (takut) yang disebabkan oleh sesuatu (Bibleworks 10, s.v. "dekhal"). Berdasarkan konteks, ketakutan dalam ayat ini disebabkan oleh Allah. Allah Yang Maha Tinggi memberikan kekuasaan sebagai raja kepada Belsyazar dan kebesaran, kemuliaan dan keluhuran kepada Nebukadnezar, dan karena kebesaran yang telah diberikan-Nya itu, maka orang-orang dari segala bangsa, suku dan bahasa akan takut dan gentar kepada raja-raja itu. Jadi, takut kepada raja karena kebesarannya sebenarnya disebabkan oleh tindakan Allah Yang Maha Tinggi yang telah memberikan kebesaran itu kepada mereka.

Kata yang sama seperti Daniel 5:19 juga dipakai dalam Daniel 6:27, dengan konteks yang berbeda. Pada konteks ini kata "takut" diserukan oleh Raja Darius (raja ke-3 pada masa pembuangan Daniel ke Babel) kepada seluruh orang-orang dari segala bangsa, suku dan bahasa yang mendiami seluruh bumi dan perintah kepada seluruh kerajaan yang ia kuasai agar takut dan gentar kepada Allahnya Daniel, sebab Dialah Allah yang hidup, yang kekal untuk selama-lamanya; pemerintahan-Nya tidak akan binasa dan kekuasaan-Nya tidak akan berakhir. Dia melepaskan dan menolong, dan mengadakan tanda dan mujizat di langit dan di bumi, Dia yang telah melepaskan Daniel dari cengkeraman singa-singa (lih. Dan. 5).

Berdasarkan perbandingan makna "takut" di dalam Daniel 1:10; 5:19 dan 6:27, Allah sebenarnya ingin menunjukkan dan membuktikan siapa sebenarnya sosok yang layak "ditakuti" dan hal ini ditegaskan melalui ketaatan orang-orang yang percaya kepada-Nya. Jadi, ketaatan seseorang kepada Allah menunjukkan kebesaran Allah Yang Maha Tinggi yang memiliki kedudukan tertinggi daripada segala kedudukan yang ada. Sehingga, sudah selayaknya penghormatan tertinggi diberikan kepada Yang Empunya Kedudukan Tertinggi.

Dalam Daniel 10:7; 12; 19, ketaatan Daniel ditunjukkan melalui ketekunan dalam doa. Dalam ketekunan doa yang dilakukan oleh Daniel, TUHAN memberikan suatu penglihatan yang mengakibatkan: 1) Orang-orang yang ada bersama-sama dengan Daniel ditimpa ketakutan besar, sehingga mereka lari bersembunyi. Dalam hal ini hanya Daniel saja yang melihat penglihatan tersebut; 2) Daniel juga mengalami ketakutan akibat penglihatan yang dialaminya. Ketakutan Daniel digambarkan dalam ayat 8-11 dan 15: hilang kekuatannya, menjadi pucat, tidak ada lagi kekuatan padanya, Daniel jatuh pingsan tertelungkup dengan mukanya ke tanah, bangun sambil bertumpu pada lutut tangannya serta berdiri dengan gemetar, Daniel menundukkan muka ke tanah dan terkelu (terdiam/tidak dapat berkata-kata dengan mendadak karena sangat terkejut sangat ketakutan; lih. Dan. 10:7,12,19).

Kata "takut" dari frasa ketakutan yang digunakan dalam Daniel 10:7 berasal dari חרָרָדָה (kharadah) yang berarti takut, gelisah, gemetar, menggigil atau bergetar (Bibleworks 10, s.v. "kharadah"). Hal ini menggambarkan bukan ketakutan dalam arti menghormati, atau hormat melainkan ketakutan karena adanya objek yang 
memberikan dampak psikologis yang besar bagi subjek yang mengalami hal tersebut (pemahaman ini berdasarkan konteks narasi Dan. 10:7). Dengan kata lain, adanya perasaan takut, gelisah, gemetar menghadapi sesuatu yang dianggap akan mendatangkan bencana, sehingga tidak dapat berbuat sesuatu untuk menghadapinya, selain melarikan diri untuk bersembunyi (Dan. 10:7 menegaskan bahwa hanya Daniel yang melihat penglihatan itu, tetapi orang-orang yang bersamasama dengan Daniel, tidak melihatnya; sebaliknya mereka ditimpa oleh ketakutan yang besar, sehingga mereka lari bersembunyi).

Sedangkan kata "takut" yang digunakan di dalam Daniel 10:12; 19, menggunakan kata yang sama dengan 1:10 yaitu ירָּ (yare') yang berarti fearing, reverent, afraid (takut, hormat; Bibleworks 10, s.v. "yare"). Jika melihat kisah dalam Daniel 10, kata "takut" menunjuk pada apa yang dialami oleh Daniel dan orang-orang yang bersamanya waktu itu sehingga pada ayat 19 malaikat menggunakan kata yang sama untuk memberitahu agar tidak takut.

Sekalipun Daniel juga merasakan ketakutan yang sama, namun sikap Daniel dan orang-orang yang bersamanya berbeda. Daniel melihat penglihatan itu tetapi orangorang itu tidak; Mereka ditimpa oleh ketakutan yang besar, sedangkan Daniel tidak; mereka lari bersembunyi, Daniel tinggal seorang diri. Bahkan dalam kesendiriannya di tengah-tengah perasaan itu, Daniel kehilangan kekuatannya, ia menjadi pucat sama sekali, bahkan ditekankan kembali tidak ada lagi kekuatan padanya. Ada beberapa kemungkinan mengapa Daniel mengalami hal yang demikian: 1) la merasa dirinya adalah orang berdosa sehingga tidak layak berdiri di hadapan kemuliaan Allah; 2) Daniel berhadapan dengan satu tugas yang dirasakannya sedemikian mengerikan, tetapi sekaligus mulia yang tidak dapat ditolaknya (Wallace, 2010, p. 256).

Dari bagian ini, penulis melihat bahwa respons setiap orang terhadap rasa takut itu berbeda-beda. Ada yang takut kemudian melarikan diri, namun ada juga yang ketakutan namun tidak dapat berbuat apa-apa. Dalam ketakutannya, Daniel dikuatkan oleh malaikat TUHAN yang mendatanginya dan berkata sebanyak dua kali untuk, "jangan takut, Daniel..." (ay. 12a dan 19a). Ini adalah sebuah pernyataan yang mengungkapkan bahwa di dalam ketakutan hamba-Nya, Tuhan senantiasa menghibur, menguatkan, bahkan memberi keberanian di dalam hati umat-Nya. Kata itu merupakan kata-kata yang sangat menghibur para pekerja di ladang TUHAN (Jaffray, 2008, p. 173,178).

Daniel merasa takut dan berpikir mustahil untuk pekerjaan yang diberikan kepada-Nya dengan melihat segala keterbatasan yang dimilikinya, namun perkataan itu di satu sisi menimbulkan kekuatan dan keteguhan hati karena TUHAN-lah yang memberikannya.

Jadi, pengenalan akan siapa yang "ditakuti" memberikan dampak besar kepada ketaatan seseorang. Rasa takut tanpa pengenalan dan pengakuan yang benar akan Tuhan akan membawa seseorang untuk menyelamatkan diri, sedangkan pengenalan yang benar dan pengakuan yang benar akan Tuhan serta pengenalan yang benar 
akan diri sendiri akan membawa seseorang untuk melihat kepada TUHAN. Hal inilah yang menjadi orientasi dan motivasi seseorang untuk menaati TUHAN.

Dengan kata lain, ketaatan terhadap seseorang didasarkan kepada seberapa jauh pengenalan dan pengakuan orang tersebut terhadap oknum yang ditaati dan juga disertai oleh pengenalan yang benar akan diri sendiri. Jadi, pengenalan dan pengakuan akan siapa TUHAN serta pengenalan yang benar akan diri sendiri mendahului rasa takut; dan rasa takut mendahului ketaatan dan ketaatan menyatakan kemuliaan TUHAN. Rasa takut yang salah cenderung membawa seseorang untuk kembali kepada dirinya sendiri, sedangkan rasa takut yang benar cenderung membawa seseorang kembali kepada Allah.

\section{Implementasi Rohani Ketaatan Menurut Kitab Daniel}

Pengenalan akan TUHAN menjadi kunci utama ketaatan Daniel dan temantemannya. Ketaatan tersebut diwujudkan melalui ketetapan hati mereka untuk memilih mendengarkan suara TUHAN dari pada suara penguasa pada waktu itu. Penulis mencatat ada beberapa poin penting makna ketaatan menurut kitab Daniel.

\section{Ketaatan Berarti Menetapkan Hati Untuk Hidup Dalam Kekudusan (Dan. 1:8)}

Dalam pasal 1 teks mencatat bahwa ketetapan hati diawali dan dilakukan oleh Daniel (ay. 8). Ketetapan hati Daniel ini dijelaskan melalui sebuah keterangan untuk tidak menajiskan dirinya dengan santapan raja dan dengan anggur yang biasa diminum raja.

Kata "menetapkan hati" yang digunakan dalam ayat ini berasal dari kata שוֹם (sum) atau שִים (sim) yang memiliki arti to put (menaruh), place (menempatkan), set (setelan), appoint (menentukan/menetapkan; Bibleworks 10, s.v. "sum"). Dalam beberapa terjemahan kata tersebut diterjemahkan sebagai bertekad (BIS); made up his mind (meneguhkan pikirannya/pendiriannya; NET); resolved not to (ketetapan hati; NIV); purposed in his heart (maksud dalam hati-secara sengaja; ASV); determined (menentukan; CSB); sudah bertekad (FAYH); sudah berniat (TL); tidak mau (VMD); dalam hatinya berketetapan (AYT).

Ketika Daniel menetapkan hatinya hal itu berarti ia mempunyai kepastian, ketentuan, keteguhan, tekad, serta kebulatan hati untuk tidak menajiskan dirinya dengan santapan raja dan dengan anggur yang biasa diminum raja. Menurut Bob Utley, ada dua kemungkinan mengapa Daniel tidak mau menajiskan dirinya dengan makanan dan minuman raja: (1) karena makanan telah dipersembahkan kepada berhala Babilonia atau (2) karena kekangan hukum makanan Yahudi (lih. Im. 11; UI. 14; Utley, 2005, p. 14). Itulah sebabnya sangat masuk akal jika santapan dan minuman raja merupakan sebuah pelanggaran terhadap hukum Taurat, merupakan sebuah dosa di hadapan Allah. Bahkan ada yang menyimpulkan bahwa sebenarnya yang diperjuangkan Daniel bukanlah proyek manusia sebagaimana raja dalam adegan pada pasal 1 ini, melainkan tradisi religius (Venantius, 2020, pp. 213-37). 
Oleh karena itu, ketetapan hati Daniel untuk tidak menajiskan dirinya dengan dosa menggambarkan kebulatan hatinya untuk serius mempertahankan dan menjaga kekudusan hidupnya sesuai dengan tradisi religius yang berfondasi pada ketetapan hukum Taurat.

Tetapi hal yang cukup mengejutkan ialah bahwa Daniel tidak keberatan untuk:

1) Perubahan namanya menjadi Beltsazar, yang mencerminkan dewa kafir (Utley, 2005, p. 14). Padahal nama Daniel berasal dari kata Ibrani daniyye'l, atau dani'el, yang berarti "hakimku ialah Allah" atau "Allah adalah hakimku" (Nggebu, 2007, p. 158). Beltsazar berarti, "menjadi hamba Dewa Bel" atau "tentara Baal." Ada kemungkinan Beltsazar mungkin berarti "semoga dewa Bel melindungi raja" (Balchim, dkk., 1985, s.v. "Daniel") sehingga hal ini cukup mengherankan, tetapi dapat dipahami dengan melihat situasi yang ada.

2) Kajiannya akan berbagai tulisan dan hikmat Babel (Utley, 2005, p. 14), tapi Daniel hanya mengekspresikan tradisi Yahudinya dalam kaitannya dengan pola makannya dan ini merupakan pengalaman lintas-budaya yang sama dengan pengalaman Yusuf dan Musa di Mesir. Hal ini memperlihatkan adanya preseden.

Melalui belajar bahasa baru, mengikuti gaya hidup baru dengan perubahan pola makan, dan menerima nama baru (Dan. 1:4-7), Daniel diperlengkapi untuk mengabdi dalam pemerintahan baru dan asing (Deventer, 2017). Situasi ini menjelaskan bahwa Daniel dan orang Yahudi lainnya diperhadapkan pada situasi sulit untuk menetapkan sebuah pilihan. Daniel secara khusus diperhadapkan untuk memilih taat pada perintah raja atau tetap mengikuti perintah Allah. Pilihan ini menjadi sebuah dilema yang dihadapi oleh Daniel dengan risiko besar yang ada di hadapannya.

Melalui penjelasan di atas, penulis menyimpulkan bahwa sesungguhnya Tuhan menghendaki agar umat-Nya hidup dalam kekudusan dan untuk mencapainya dibutuhkan ketaatan. Namun ketaatan dalam mengikuti perintah Tuhan memiliki resiko yang besar. Karena itu, ketetapan hati kepada Tuhan untuk tetap taat mengambil peran yang begitu besar sehingga seseorang pada akhirnya dimampukan untuk berani melangkah dengan membuat sebuah keputusan yang benar sekalipun dalam keadaan terjepit.

\section{Ketaatan berarti Tidak Menyembah Berhala (Dan. 3:17-18)}

Kesulitan dan kesukaran yang Allah izinkan terjadi dan dialami oleh Sadrakh, Mesakh, dan Abednego (Hananya, Misael, dan Azarya), adalah untuk menguji dan membuktikan iman mereka kepada Allah. Dalam pasal 3, mereka dibuang ke dalam perapian yang menyala-nyala karena menolak untuk menyembah berhala. Seperti penjelasan pada poin sebelumnya, hal ini dikarenakan ketetapan hati yang telah mereka buat untuk tidak menajiskan dirinya dengan dosa. Pada tahap ini tantangannya bukan pada makanan dan minuman, melainkan pada penyembahan berhala, yang jelas-jelas dilarang oleh Allah dalam perintah kedua dari sepuluh perintah Tuhan. 
Sebelum mereka masuk ke dapur api, mereka berkata kepada Raja Nebukadnezar bahwa, "andaikata Allah tidak menyelamatkan mereka, mereka tetap menolak untuk menyembah berhalanya raja" (ay. 17), artinya baik selamat maupun tidak dari perapian yang menyala-nyala, iman mereka sudah bulat untuk tidak menyembah dan memuja ilah lain selain TUHAN. Ini merupakan sebuah pernyataan iman dari mereka yang sungguh-sungguh menetapkan hatinya kepada TUHAN.

Awal kalimat mereka mengatakan, "... tidak ada gunanya kami memberi jawab kepada tuanku dalam hal ini" (ay. 16). Artinya sekalipun ancaman yang diberikan oleh raja begitu menggetarkan karena berisiko kepada kematian, tetapi sama sekali tidak menggoyahkan iman mereka kepada TUHAN. Ketiga orang ini memutuskan untuk taat kepada Tuhan dan menolak untuk sujud kepada berhala. Mereka tidak membuat keputusan itu karena mereka percaya bahwa Allah akan menyelamatkan mereka dari ancaman Nebukadnezar, melainkan mereka membuat keputusan itu karena mereka tahu akan menyenangkan hati TUHAN.

Sebenarnya Nebukadnezar dapat memberikan akibat yang terburuk pada mereka yaitu kematian, tetapi tidak memiliki kekuatan untuk membuat mereka menyembah patungnya. Dalam hal ini, "kekuatan" tiga orang ini lebih besar dari miliknya, dan pengakuan Nebukadnezar akan hal ini memicu kemarahannya (Waller, 2020, pp. 327-46).

Dalam Daniel 3:17 mereka mengingatkan raja bahwa Allah sanggup menyelamatkan mereka bila itu kehendak-Nya, tetapi kalaupun tidak, mereka tetap tidak akan sujud (ay. 18). Mungkin mereka telah mengharapkan akan mati, namun mereka tidak menuntut balasan dari ketaatan mereka. Mereka sangat percaya bahwa Tuhan sanggup (ay. 17), tetapi mereka tidak sedang menjadi sombong dengan menuntut sebuah mukjizat (ay. 18). Iman mereka berdasar di dalam TUHAN, bukan didasari oleh keadaan.

\section{Ketaatan berarti Mengandalkan TUHAN melalui Doa (Dan. 6:11)}

Daniel dikenal sebagai seorang tokoh yang sangat menyukai dan menikmati doa. Berdasarkan teks dalam Daniel 6:11, diketahui bahwa Daniel adalah seorang yang sering berdoa, bahkan dikatakan, "tiga kali sehari ia berlutut, berdoa serta memuji Allahnya, seperti yang biasa dilakukannya" artinya doa menjadi kegiatan rutin yang dilakukan oleh Daniel.

Di dalam Doa Daniel memuji Allah (6:11), memohon kepada Allah (6:12), mengaku dosanya dan dosa bangsanya serta menyampaikan kepada TUHAN segala permohonannya (9:20). Terkadang sambil berdoa ia berpuasa dan mengenakan kain kabung serta abu (tanda kedukaan dan penyesalan).

Doa adalah kebaktian yang mencakup segala sikap roh manusia dalam pendekatannya kepada Allah (Douglas, dkk. (ed.), 1997, s.v. "Doa"). Billy Graham dalam bukunya pernah mengatakan, "Doa itu adalah untuk setiap saat dalam hidup kita, tidak hanya pada saat menderita atau bersukacita. Doa adalah benar-benar merupakan suatu tempat di mana anda bertemu dengan Allah dalam percakapan 
yang sungguh-sungguh"; "Doa adalah hal tertinggi yang bisa dilakukan oleh perkataan" (Graham, Toney, 2014, p. 286).

Doa tidak lepas dari kehidupan Daniel, bukan hanya dalam keadaan susah tetapi juga dalam keadaan makmur, bukan hanya dalam keadaan bahaya melainkan juga pada masa-masa aman, bahkan hingga masa tuanya pun Daniel masih tetap setia berdoa. Daniel terus berdoa karena dia sadar tanpa TUHAN, dia bukan siapa-siapa, bukan apa-apa, dan tidak dapat melakukan apa-apa.

Doa harus dilakukan setiap waktu dalam segala kondisi dan situasi. Penulis setuju dengan pendapat Billy Graham mengenai doa, bahwa "kita harus berdoa dalam masa-masa kesukaran, kalau tidak, kita akan kehilangan iman dan kepercayaan. Kita harus berdoa dalam masa-masa kemakmuran, kalau tidak, kita akan menjadi sombong dan angkuh. Kita harus berdoa dalam masa-masa bahaya, kalau tidak, kita akan menjadi ketakutan dan ragu-ragu. Kita harus berdoa pada masa-masa aman, supaya kita tidak bergantung pada diri sendiri" (Graham, Toney, 2014, p. 291).

Penulis meyakini bahwa tujuan Daniel berdoa selain menyatakan hubungan yang dekat dengan Allah; juga menyatakan pergumulan Daniel agar ia tetap senantiasa dimampukan untuk taat dalam segala keadaan baik saat menghadapi masa-masa kesukaran dan bahaya, saat ia berada dalam lingkungan orang-orang yang tidak mengenal TUHAN, saat nyawanya teracam dibunuh, saat dilemparkan ke gua singa, agar ia tidak kehilangan iman dan kepercayaan kepada TUHAN, serta tidak menjadi takut dan ragu. Dan dalam masa kemakmuran dan masa aman, ketika ia diangkat kedudukan yang tinggi atas seluruh Babel, dan memperoleh penghormatan oleh seluruh rakyat Babel, agar ia tidak menjadi sombong dan angkuh, serta bergantung pada diri sendiri. Itulah sebabnya Daniel terus berdoa sepanjang umurnya, karena sadar bahwa dia butuh TUHAN di dalam kehidupannya.

\section{KESIMPULAN}

Kehidupan sebagai orang Kristen tentunya penuh dengan tantangan iman. Iman yang benar akan membawa seseorang pada sikap hidup yang benar. Ketaatan menjadi hal yang begitu mahal ketika manusia menyadari siapa dirinya di hadapan TUHAN. Sebagai ciptaan, manusia tidak lebih baik dari sesamanya, sebagai orang percaya, manusia tidak dapat lebih baik di hadapan TUHAN. Hanya oleh anugerah TUHAN saja, manusia memperoleh kekuatan, kemampuan dan hikmat untuk menaati kehendak-Nya dengan setia. Tanpa itu, manusia hanyalah sebongkah tanah liat yang merasa diri kuat bertahan di tengah derasnya air yang mengalir. Pengenalan yang benar akan TUHAN akan membawa manusia untuk mengagumi siapa TUHAN, pengakuan yang benar akan siapa TUHAN akan membawa manusia untuk mengutamakan TUHAN, serta pengenalan yang benar akan diri sendiri akan membawa manusia untuk menyadari keterbatasan dan ketidakmampuannya untuk menaati TUHAN. Jadi, ketaatan dalam kitab Daniel mengajarkan kepada orang 
percaya pentingnya pengenalan yang benar, pengakuan yang benar serta penyangkalan diri yang sungguh untuk menaati kehendak Allah.

\section{KEPUSTAKAAN}

Achtemeier, Paul J. (1985). Society of Biblical Literature: Harper's Bible Dictionary. 1st ed. San Francisco: Harper \& Row, Publishers.

Baker, David L., S. M. Siahaan, dan A. A. Sitompul. (2015). Pengantar Bahasa Ibrani. Jakarta: BPK Gunung Mulia.

Balchin, John, dkk. (1985). Intisari Alkitab Perjanjian Lama dan Perjanjian Baru. Jakarta: Persekutuan Pembaca Alkitab.

Bibleworks 10.

Bromiley, Geoffrey W. (2002). The International Standard Bible Encyclopedia, Revised. Michigan: Wm. B. Eerdmans.

Deventer, H. J. M. (Hans) van. (2017). Aspects of Liminality in the Book of Daniel. Old Testament Essays, 30(2), 443-458. https://doi.org/10.17159/23123621/2017/v30n2a15.

Douglas, J. D., dkk. (ed.). (1997). Ensiklopedia Alkitab Masa Kini A-L. Jakarta: Yayasan Komunikasi Bina Kasih.

Graham, Franklin; Donna Lee Toney. (2014). Billy Graham in Quotes. Jakarta: Kairos. Jaffray, Robert Alexander. (2008). Tafsiran Kitab Daniel. Bandung: Kalam Hidup.

Kelley, Page H. (2013). Pengantar Tata Bahasa Ibrani Biblikal. Surabaya: Penerbit Momentum.

Lederach, Paul M. Daniel. (1994). Believers Church Bible Commentary. Scottdale, Pa.: Herald Press.

Lumintang, Stevi Indra, dan Danik Astuti Lumintang. (2016). Theologia Penelitian \& Penelitian Theologis. Jakarta: Geneva Insani Indonesia.

Newel, Lynne. (2000). Tafsiran Kitab Daniel. Malang: SAAT.

Nggebu, Sostenis. (2007). Dari Ur-Kasdim sampai ke Babel: Karakter 30 Tokoh Perjanjian Lama. Bandung: Kalam Hidup.

Parchem, Marek. (Desember 2018). Periodyzacja historii w Księdze Daniela. Verbum Vitae, (35), 121-44. https://doi.org/10.31743/vv.3315.

Putri, Agustin Soewitomo. (April 2017). Menstimulasi Kualitas Kehidupan Rohani dalam Meningkatkan Kemandirian Belajar Mahasiswa: Studi Refleksi Daniel 6:14. DUNAMIS: Jurnal Penelitian Teologi dan Pendidikan Kristiani, 1(2), 156-170. https://doi.org/10.30648/dun.v1i2.120.

Rindge. (2010). Jewish Identity under Foreign Rule: Daniel 2 as a Reconfiguration of Genesis 41. Journal of Biblical Literature, 129(1), 85-104. https://doi.org/10.2307/27821006.

Strong, James. (2017). The New Strong's Expanded Echaustive Concordance of The Bible. China: Thomas Nelson Publishers. 
Sutanto, Hasan. (2007). Hermeneutik: Prinsip dan Metode Penafsiran Alkitab. Malang: Literatur SAAT.

Utley, Bob. (2005). Wahyu-wahyu Perjanjian Lama: Daniel dan Zakharia. Marshall, Texas: Bible Lesson International.

Venantius, Supriyono. (2020). Inspirasi Kitab Daniel Untuk Menghadapi Stres Benturan Peradaban. Studia Philosophica et Theologica, 19(2), 213-37. https://doi.org/10.35312/spet.v19i2.82.

Wallace, Ronald S. (2010). Daniel. Jakarta: Yayasan Komunikasi Bina Kasih.

Waller, Daniel James. (Juni 2020). Sympathy for a Gentile King: Nebuchadnezzar, Exile, and Mortality in the Book of Daniel. Biblical Interpretation, 28(3), 327-46. https://doi.org/10.1163/15685152-00283P03.

Walvoord, John F., dan Roy B. Zuck. (1985). The Bible Knowledge Commentary: An Exposition of the Scriptures. Wheaton, Illnois: Victor Books. 